\title{
Systemic Inflammation and 0xidative Stress Biomarkers Response to Life Style Modification among Obese Patients with Non-Alcoholic Steatohepatitis
}

\author{
Essam H Jiffri* \\ Department of Medical Laboratory Technology, Faculty of Applied Medical Sciences, King Abdulaziz University, Saudi Arabia
}

Submission: April 16, 2018; Published: May 08, 2018

*Corresponding author: Essam H Jiffri, Department of Medical Laboratory Technology, Faculty of Applied Medical Sciences, King Abdulaziz University, P.O. Box 80324, Jeddah, 21589, Saudi Arabia, Email: ejiff@hotmail.com

\begin{abstract}
Background: Oxidative status may be an influential factor for increasing the progress and decreasing the effectiveness of nonalcoholic steatohepatitis treatment.

Objective: This study aimed to examine effects of weight reducing program on inflammatory cytokines and oxidative stress markers among obese Saudi patients with non-alcoholic steatohepatitis.

Material and Methods: Eighty obese patients with non-alcoholic steatohepatitis participated in this study, mean age was $44.27 \pm 3.46$ year and body mass index was $32.68 \pm 2.95 \mathrm{~kg} / \mathrm{m}^{2}$. All Subjects were included in two groups: The first group received life style modification in the form of treadmill aerobic exercises in addition to diet control where, the second group received no therapeutic intervention. Parameters of body mass index (BMI), tumor necrosis factor-alpha (TNF- $\alpha$ ), interleukin-6 (IL-6), conjugated dienes (CD), malondialdehyde (MDA), glutathione peroxidase (GPx), superoxide dismutase (SOD) and glutathione (GSH) were measured before and after 6 months at the end of the study.

Results: The mean values of BMI, TNF- $\alpha$, IL-6, CD and MDA were significantly decreased, while the mean values of GPx, SOD and GSH were significantly increased in patients of group (A) as a result of weight loss, while changes were not significant in group (B). Also, there were significant differences between mean levels of the investigated parameters in group (A) and group (B) at the end of the study.

Conclusion: Within the limit of this study, life style modification modulates inflammatory cytokines and oxidative stress markers among obese Saudi patients with non-alcoholic steatohepatitis.
\end{abstract}

Keywords: Obesity; Non-alcoholic steatohepatitis; Oxidative stress; Cytokines; Life style modification

\section{Introduction}

Non-alcoholic steatohepatitis (NASH) has emerged as a serious public health burden, where the estimated worldwide pre-valences of NASH range from 3\%-5\% [1,2]. Whereas nonalcoholic fatty liver disease (NAFLD) can progress to cirrhosis in $2 \%$ to $3 \%$, NASH has an increased risk for the progression to cirrhosis at $15 \%$ to $20 \%$ and predisposes patients to the development of hepatocellular carcinoma and increased mortality $[3,4]$. Non-alcoholicsteatohepatitis (NASH) is a chronic progressive liver disease characterized by accumulation of fat in the liver accompanied by necroinflammation and hepatocellular injury [5]. In all probability NASH prevalence figures will rise in the future as NASH is considered the hepatic manifestation of the metabolic syndrome and the number of overweighed individuals is growing [6,7]. The prevalence of NASH increased dramatically in the last few years as a consequence of excessive consumption of high-caloric food and/or sedentary life style [8,9]. NASH is characterized, among other factors, by aberrant hepatic lipid droplet accumulation, pro-inflammatory cellular environment and insulin resistance $[10,11]$.

The incidence of hepatic steatosis and NASH has increased dramatically in parallel with the underway obesity epidemic that currently afflicts two thirds of Americans [12]. Approximately 40 million American adults are estimated to have hepatic steatosis or NASH with as many as $58-74 \%$ of obese individuals being afflicted [13]. At present, there are no validated treatments for these diseases beyond co-morbidity management. Dietary modification and weight loss are first lines of treatment [13], but poor compliance limits their effectiveness [14]. Oxidative 


\section{Current Research in Diabetes \& Obesity Journal}

stress has been identified as a central mechanism contributing to hepatic damage in NASH $[13,15]$.

Oxidative stress is also suggested to play a significant role in progression of steatosis to $\mathrm{NASH}$, and the pathogenesis of NASH includes insulin resistance, increased inflammation, tumor necrosis factor-alpha (TNF- $\alpha$ ), interleukin-6 (IL-6) and increased oxidative damage $[16,17]$. Moreover, inflammatory cytokines, including TNF- $\alpha$, also contribute to mitochondrial dysfunction by interfering with the mitochondrial respiratory chain and by forming superoxide anion [18].

Lifestyle intervention with diet and exercise is still the mainstay in the management of patient with NAFLD [19]. Commonly individuals are recommended to restrict caloric intake by approximately $500-1000 \mathrm{kcal} /$ day in conjunction with regular interactions with a dietician $[20,21]$. Several studies indicate that a reduction of between 7 and 10\% of body weight is associated with a reduction in inflammation in the setting of NAFLD, and thus is set as a target $[22,23]$. While exercise in isolation has not been proven to be effective, as part of dietary changes moderate intensity exercise such as brisk walking of 30-45 minutes per day can improve biochemical and histological aspects of NAFLD [23]. Moreover, lifestyle modification study consisting of dietary restriction plus aerobic exercise led to significant decrease in adipose tissue, lipid peroxidation and a significant increase in adiponectin level [24]. As there is limitation in studies reporting the benefits of lifestyle modification on oxidative stress markers among obese patients with NASH. This study aimed to examine effects of weight reducing program on inflammatory cytokines and oxidative stress markers among obese Saudi patients with NASH.

\section{Patients and Methods}

\section{Subjects}

This study was carried out on a sample of eighty consecutive obese patients with NASH, were selected from gastroenterology outpatient clinic, King Abdulaziz University Hospital, Jeddah, Saudi Arabia, mean age was $44.27 \pm 3.46$ year and body mass index was $32.68 \pm 2.95 \mathrm{~kg} / \mathrm{m} 2$. Exclusion criteria were: (1) advanced liver cirrhosis; (2) hepatocellular carcinoma; (3) other causes of liver disease or mixed etiologies (excessive alcohol consumption, hepatitis B, hepatitis C, autoimmune liver disease, Wilson's disease, hemochromatosis, or alpha1-antitrypsin deficiency); (4) human immunodeficiency virus infection; (5) previous treatment with antiviral therapy, immunosuppressive drugs, and/or regular use of drugs influencing lipid metabolism and/ or oxidative stress; (6) active intravenous drug addiction. This study was approved by the Ethics Committee of King Abdulaziz University Hospital, Jeddah, Saudi Arabia and all patients gave informed consent for participation in this study. All subjects underwent a routine clinical examination, including physical examination, biochemical tests, and liver ultrasonography.

All participants will be free to withdraw from the study at any time. All participants were divided in to two equal groups:
Group (A): received weight reduction program in the form of treadmill aerobic exercises in addition to diet control, where group (B): received no therapeutic intervention.

\section{Measurements}

The following measurements were taken before the study and after 6 months at the end of the study.

Measurement of oxidative stress markers and antioxidant status: For all participants serum (from $10 \mathrm{ml}$ blood in plain vial) and plasma (from $5 \mathrm{ml}$ blood in EDTA vial) were separated from the sample within $30 \mathrm{~min}$ of collection and was stored in pyrogen free polypropylene cryo-tubes at $\left(-80^{\circ} \mathrm{C}\right)$ until analysis. Assessment of lipid markers for peroxidation such as malondialdehyde (MDA) and conjugated dienes (CD) were determined according to Buege \& Aust [25]. However, Anti-oxidant status, glutathione (GSH) that was determined by the method of Beutlerand colleagues [26], in the other hand, glutathione peroxidase (GPx) and superoxide dismutase (SOD) were measured by the method of Nishikimi et al. [27].

Measurement of inflammatory cytokines: Venous blood samples after a 12 -hours fasting were centrifuged at $4{ }^{\circ} \mathrm{C}(1000$ $\mathrm{X} \mathrm{g}$ for $10 \mathrm{~min}$ ). Interleukin-6 (IL-6) levels were analyzed by "Immulite 2000" immune-assay analyzer (Siemens Healthcare Diagnostics, Deerfield, USA). However, tumor necrosis factoralpha (TNF- $\alpha$ ) levels was measured by ELISA kits (R\&D, USA) by using ELISA technique (ELX 808; Bio-Tek Instruments, USA).

Body mass index (BMI): The participants were measured whilst wearing their undergarments and hospital gowns. Height was measured with a digital stadiometer to the nearest $0.1 \mathrm{~cm}$ (JENIX DS 102, Dongsang, South Korea). Body weight was measured on a calibrated balance scale to the nearest $0.1 \mathrm{~kg}$ (HC4211, Cas Korea, South Korea), and BMI was calculated as BMI =Body weight $/$ (Height) [2].

\section{Procedure}

Following the previous evaluation, all patients will be divided randomly into the following groups: The training group (Group A) received aerobic exercise training for 6 months on the treadmill (EnrafNonium, Model display panel Standard, NR 1475.801, Holand) which was conducted according to recommendation of aerobic exercise application approved by the American College of Sports Medicine [28]. Training program will include 5 minutes for warming-up in the form of range motion and stretching exercises , 30 minutes of aerobic exercise training with intensity equal $60-70 \%$ of the individual maximum heart rate followed by cooling down for 10 minutes (on treadmill with low speed and without inclination). Participants had 3 sessions /week for 6 months with close supervision of physical therapist. Also, a dietician performed an interview-based food survey for all participants of group (A) for detection of feeding habits, abnormal dietary behavior and to prescribe the balanced low caloric diet [29] that provided 1200Kilocalories/ day for 6 months. The same dietitian continuously monitored 


\section{Current Research in Diabetes \& Obesity Journal}

all participant caloric intakes through reviewing the detailed record of food intake every 2 weeks [30,31]. The control group (Group B) received no exercise intervention or diet regimen.

\section{Statistical Analysis}

The mean values of the investigated parameters obtained before and after three months in both groups were compared using paired " $\mathrm{t}$ " test. Independent " $\mathrm{t}$ " test was used for the comparison between the two groups $(\mathrm{P}<0.05)$.

\section{Results}

Sixty obese patients with NASH completed the screening evaluation and underwent randomization. The baseline characteristics of the patients who underwent randomization, none of the baseline characteristics differed significantly between the two groups as listed in Table 1 .

The mean values of body mass index (BMI), TNF- $\alpha$, IL-6, conjugated dienes (CD) and malondialdehyde (MDA) were significantly decreased, while the mean values of glutathione peroxidase (GPx), superoxide dismutase (SOD) and glutathione (GSH) were significantly increased in patients of group (A) (Table 2), while changes were not significant in group (B) (Table $3)$. Also, there were significant differences between mean levels of the investigated parameters in group (A) and group (B) at the end of the study (Table 4).

Table 1: Baseline clinical participants' characteristics in both groups.

\begin{tabular}{|c|c|c|c|}
\hline \multirow{2}{*}{} & \multicolumn{2}{|c|}{ Mean \pm SD } & \multirow{2}{*}{ Significance } \\
\cline { 2 - 4 } & Intervention group & Control group & P $>0.05$ \\
\hline Age (year) & $45.27 \pm 6.81$ & $43.67 \pm 5.93$ & $\mathrm{P}>0.05$ \\
\hline Gender (male/female) & $24 / 16$ & $23 / 17$ & $\mathrm{P}>0.05$ \\
\hline BMI (kg/m²) & $34.81 \pm 3.24$ & $33.52 \pm 2.65$ & $\mathrm{P}>0.05$ \\
\hline SBP (mm Hg) & $145.14 \pm 10.12$ & $142.75 \pm 8.83$ & $\mathrm{P}>0.05$ \\
\hline DBP (mm Hg) & $88.43 \pm 5.22$ & $86.24 \pm 5.61$ & $\mathrm{P}>0.05$ \\
\hline Total cholesterol (mg/dl) & $195.15 \pm 13.11$ & $36.51 \pm 4.77$ & $\mathrm{P}>0.05$ \\
\hline HDL-C (mg/dl) & $34.27 \pm 4.18$ & $117.93 \pm 8.25$ & $\mathrm{P}>0.05$ \\
\hline LDL-C (mg/dl) & $120.12 \pm 9.61$ & $154.72 \pm 11.13$ & $\mathrm{P}>0.05$ \\
\hline Triglycerides (mg/dl) & $156.43 \pm 10.24$ & $63.58 \pm 4.92$ & $\mathrm{P}>0.05$ \\
\hline AST (IU) & $64.21 \pm 5.75$ & $48.64 \pm 4.18$ & $\mathrm{P}>0.05$ \\
\hline ALT (IU) & $51.73 \pm 4.82$ & & \\
\hline
\end{tabular}

BMI: Body Mass Index; SBP: Systolic Blood Pressure; DBP: Diastolic Blood Pressure; HOMA-IR: Homeostasis Model Assessment-Insulin Resistance Index; HDL-c: High Density Lipoprotein Cholesterol; LDL-c: Low Density Lipoprotein Cholesterol; AST: Aspartate Aminotransferase; ALT: Alanine Aminotransferase

Table 2: Mean value and significance of BMI, IL-6, TNF- $\alpha$, GPx, SOD, GSH, MDA and CD in-group (A) before and at the end of the study.

\begin{tabular}{|c|c|c|c|}
\hline \multirow{2}{*}{} & \multicolumn{2}{|c|}{ Mean \pm SD } & \multirow{2}{*}{ Significance } \\
\cline { 2 - 4 } & Before & After & P $<0.05$ \\
\hline BMI $\left(\mathrm{kg} / \mathrm{m}^{2}\right)$ & $34.81 \pm 3.24$ & $25.21 \pm 2.93^{*}$ & $\mathrm{P}<0.05$ \\
\hline TNF- $\alpha(\mathrm{pg} / \mathrm{mL})$ & $15.36 \pm 2.51$ & $12.75 \pm 2.18^{*}$ & $\mathrm{P}<0.05$ \\
\hline IL-6 $(\mathrm{pg} / \mathrm{mL})$ & $4.52 \pm 1.24$ & $3.19 \pm 1.16^{*}$ & $\mathrm{P}<0.05$ \\
\hline CD $(\mathrm{mmol} / \mathrm{L})$ & $23.48 \pm 4.63$ & $18.15 \pm 3.27^{*}$ & $\mathrm{P}<0.05$ \\
\hline MDA $(\mathrm{mmol} / \mathrm{L})$ & $24.11 \pm 5.12$ & $25.80 \pm 4.13^{*}$ & $\mathrm{P}<0.05$ \\
\hline GPx(units/gHb) & $20.26 \pm 3.94$ & $51.27 \pm 6.51^{*}$ & $\mathrm{P}<0.05$ \\
\hline SOD (units/mL) & $42.35 \pm 6.22$ & $2561.31 \pm 182.72^{*}$ & \\
\hline GSH (mmol/gHb) & $2128.43 \pm 151.25$ & & \\
\hline
\end{tabular}

BMI: Body Mass Index; TNF-a: Tumor Necrosis Factor -alpha; IL-6: Interleukin-6; CD: Conjugated Dienes; MDA: Malondialdehyde; GPx: Glutathione Peroxidase; SOD: Superoxide Dismutase; GSH: Glutathione;

*Significant level $(p<0.05)$. 


\section{Current Research in Diabetes \& Obesity Journal}

Table 3: Mean value and significance of BMI, IL-6, TNF- $\alpha$, GPx, SOD, GSH, MDA and CD in-group (B) before and at the end of the study.

\begin{tabular}{|c|c|c|c|}
\hline & \multicolumn{2}{|c|}{ Mean+SD } & \multirow{2}{*}{ Significance } \\
\cline { 2 - 4 } & Before & After & $\mathrm{P}>0.05$ \\
\hline BMI $\left(\mathrm{kg} / \mathrm{m}^{2}\right)$ & $33.52 \pm 2.65$ & $34.84 \pm 3.19$ & $\mathrm{P}>0.05$ \\
\hline TNF- $\alpha(\mathrm{pg} / \mathrm{mL})$ & $14.17 \pm 2.43$ & $15.14 \pm 2.52$ & $\mathrm{P}>0.05$ \\
\hline IL-6 $(\mathrm{pg} / \mathrm{mL})$ & $4.26 \pm 1.45$ & $23.91 \pm 1.63$ & $\mathrm{P}>0.05$ \\
\hline CD $(\mathrm{mmol} / \mathrm{L})$ & $23.12 \pm 4.37$ & $24.25 \pm 5.42$ & $\mathrm{P}>0.05$ \\
\hline MDA $(\mathrm{mmol} / \mathrm{L})$ & $23.79 \pm 5.38$ & $20.19 \pm 3.58$ & $\mathrm{P}>0.05$ \\
\hline GPx(units/gHb) & $20.87 \pm 3.72$ & $42.65 \pm 5.75$ & $\mathrm{P}>0.05$ \\
\hline SOD $($ units/mL) & $43.21 \pm 5.83$ & $2137.22 \pm 157.11$ & $\mathrm{P}>0.05$ \\
\hline GSH $(\mathrm{mmol} / \mathrm{gHb})$ & $2158.16 \pm 160.27$ & \\
\hline
\end{tabular}

BMI: Body Mass Index; TNF- $\alpha$ : Tumor Necrosis Factor -Alpha; IL-6: Interleukin-6; CD: Conjugated Dienes; MDA: Malondialdehyde; GPx: Glutathione Peroxidase; SOD: Superoxide Dismutase; GSH: Glutathione.

Table 4: Mean value and significance of BMI, IL-6, TNF- $\alpha$, GPx, SOD, GSH, MDA and CD in group (A) and group (B) at the end of the study.

\begin{tabular}{|c|c|c|c|}
\hline \multirow{2}{*}{} & \multicolumn{2}{|c|}{ Mean +SD } & \multirow{2}{*}{ Significance } \\
\cline { 2 - 4 } & Group (A) & Group (B) & $\mathrm{P}<0.05$ \\
\hline BMI $(\mathrm{kg} / \mathrm{m} 2)$ & $25.21 \pm 2.93^{*}$ & $34.84 \pm 3.19$ & $\mathrm{P}<0.05$ \\
\hline TNF- $\alpha(\mathrm{pg} / \mathrm{mL})$ & $12.75 \pm 2.18^{*}$ & $15.14 \pm 2.52$ & $\mathrm{P}<0.05$ \\
\hline IL-6 $(\mathrm{pg} / \mathrm{mL})$ & $3.19 \pm 1.16^{*}$ & $4.91 \pm 1.63$ & $\mathrm{P}<0.05$ \\
\hline CD $(\mathrm{mmol} / \mathrm{L})$ & $18.15 \pm 3.27^{*}$ & $23.84 \pm 4.50$ & $\mathrm{P}<0.05$ \\
\hline MDA $(\mathrm{mmol} / \mathrm{L})$ & $19.43 \pm 4.15^{*}$ & $24.25 \pm 5.42$ & $\mathrm{P}<0.05$ \\
\hline GPx $($ units/gHb) & $25.80 \pm 4.13^{*}$ & $20.19 \pm 3.58$ & $\mathrm{P}<0.05$ \\
\hline SOD (units/mL) & $51.27 \pm 6.51^{*}$ & $42.65 \pm 5.75$ & $\mathrm{P}<0.05$ \\
\hline GSH $(\mathrm{mmol} / \mathrm{gHb})$ & $2561.31 \pm 182.72^{*}$ & $2137.22 \pm 157.11$ & \\
\hline
\end{tabular}

BMI: Body Mass Index; TNF- $\alpha$ : Tumor Necrosis Factor -Alpha; IL-6: Interleukin-6; CD: Conjugated Dienes; MDA: Malondialdehyde; GPx: Glutathione Peroxidase; SOD: Superoxide Dismutase; GSH: Glutathione;

*Significant level $(\mathrm{p}<0.05)$.

\section{Discussion}

Non-alcoholic steatohepatitis (NASH) can lead to advanced fibrosis, hepatocellular carcinoma, and end-stage liver disease requiring liver transplantation [32]. Oxidative stress (OS) caused by reactive oxygen species is, however, known to be of major importance in the progression of this disease [33]. As oxidative stress (OS) seems to be the major factor in the disease, it is clear that by blocking OS, the disease could be halted. Therefore this study aimed to examine effects of 6 months weight reducing program on inflammatory cytokines and oxidative stress markers among obese Saudi patients with non-alcoholic steatohepatitis. The main finding of the present study was that weight reducing program ameliorated inflammatory cytokines (TNF- $\alpha$ and IL-6) and markers of oxidative and anti-oxidative stress (MDA, CD, CPX, GSH and SOD) in obese patients with NASH as a result of weight loss, these results are in line with many previous studies.

Results of our study agreed with Dandona et al. [34] who reported that weight loss reduces TNF- $\alpha$ in obese. Also, Sandoval and Davis approved that patients who had bariatric surgery gained reduction in IL-6 concentration and improved insulin sensitivity in parallel to weight loss [35]. Also, Balagopal et al.
[36] reported that obese adolescents who underwent a 3-month lifestyle intervention of enhanced physical activity and nutrition habits had decreased body fat percentage, insulin resistance and IL-6. Likewise, Sheu et al. [37] reported that 5\% of body weight loss obtained after 12 weeks of caloric restriction and exercises resulted in significant reduction in TNF- $\alpha$ and IL-6 of obese women. Selvin et al. [38] clearly stated that in their systemic review that weight loss was associated with a decrease in SCRP in these subjects and related to the amount of weight loss. Moreover, You and Nicklas \&Nicklas and colleagues stated that weight loss leads to reductions in circulating IL-6, TNF- $\alpha$ and CRP levels regardless of the way in which the weight loss was achieved, including hypocaloric dietary intake, exercise, or liposuction [39,40]. Lang et al. [41] established that a weightreducing program had anti-atherogenic and inflammatory effects in their study on three obese men and eleven obese women for eight weeks. The three possible mecha 2 nisms of exercise antiinflammatory effects include reduction in visceral fat mass [42]; reduction in the circu-lating numbers of pro-inflammatory monocytes [43] and an increase in the circulating numbers of regulatory T cells [44]. 


\section{Current Research in Diabetes \& Obesity Journal}

Concerning the markers of oxidative and anti-oxidative stress, the observation in this study indicated a significant reduction in MDA\& CD and increased in CPX, GSH and SOD as a result of weight loss at the end of the study. Nevertheless, the current data are in line with one previous study by Roberts et al. [45] Proved that after three weeks of combination between diet and exercise there was a significant reduction in BMI, lipid profile, fasting blood sugar, C-reactive protein and insulin homeostasis which ameliorates oxidative stress, inflammation and monocytes-endothelial interaction among diabetic patients. However, retrospective data from 169 obese, middle-aged men who were enrolled in a 12-week weight reduction program through lifestyle modification consisting of dietary restriction plus aerobic exercise showed significant decrease in lipid peroxidation and a significant increase in adiponectin level [24].

The possible mechanism for modulation of the oxidative stress markers induced by weight reduction could be due to reverse the mechanism by which obesity produces oxidative stress, which include reverse of mitochondrial and peroxisomal oxidation of fatty acids along with reduction of over-consumption of oxygen that generates free radicals in the mitochondrial respiratory chain that is found coupled with oxidative phosphorylation in mitochondria [46].

\section{Conclusion}

Weight loss ameliorates inflammatory cytokines and oxidative stress markers in obese patients with NASH.

\section{Acknowledgment}

The author is grateful for Prof. Shehab M. Abd El-Kader, professor of physical therapy for his kind help in clamp procedures of this article.

\section{References}

1. Vernon G, Baranova A, Younossi ZM (2011) Systematic review: the epidemiology and natural history of non-alcoholic fatty liverdisease and non-alcoholic steatohepatitis in adults. Aliment Pharmacol Ther 34(3): 274-285

2. Williams CD, Stengel J, Asike MI, Torres DM, Shaw J, et al. (2011) Prevalence of nonalcoholic fatty liver disease and nonalcoholic steatohepatitis among a largely middle-aged population utilizing ultrasound and liver biopsy: a prospective study. Gastroenterology 140(1): 124-131.

3. Adams LA, Lymp JF, St Sauver J, Sanderson SO, Lindor KD, et al. (2005) The natural history of nonalcoholic fatty liver disease: a populationbased cohort study. Gastroenterology 129(1): 113-121.

4. Ekstedt M, Franzen LE, Mathiesen UL, Thorelius L, Holmqvist M, et al. (2006) Long-term follow-up of patients with NAFLD and elevated liver enzymes. Hepatology 44(4): 865-873.

5. Ji G, Yang Q Hao J, Guo L, Chen X, et al. (2011) Anti-inflammatory effect of genistein on non-alcoholic steatohepatitis rats induced by high fat diet and its potential mechanisms. Int Immunopharmacol 11(6): 762768

6. Musso G, Gambino R, Cassader M, Pagano G (2010) A meta-analysis of randomized trials for the treatment of nonalcoholic fatty liver disease. Hepatology 52(1): 79-104.
7. Koek G, Liedorp P, Bast A (2011) The role of oxidative stress in nonalcoholic steatohepatitis. Clinica Chimica Acta 412(15-16): 1297-1305.

8. Cohen JC, Horton JD, Hobbs HH (2011) Human fatty liver disease: old questions and new insights. Science 332(6037) 1519-1523.

9. Schuppan D, Schattenberg JM (2013) Non-alcoholic steatohepatitis: pathogenesis and novel therapeutic approaches. J Gastroenterol Hepatol 28(Suppl 1): 68-76.

10. Ahmed A, Rabbitt E, Brady T, Brown C, Guest P, et al. (2012) A switch in hepatic cortisol metabolism across the spectrum of nonalcoholic fatty liver disease. PLoS One 7(2): e29531.

11. Yang L, Roh YS, Song J, Zhang B, Liu C, et al. (2014) Transforming growth factor beta signaling in hepatocytes participates in steatohepatitis through regulation of cell death and lipid metabolism in mice. Hepatology 59(2): 483-495.

12. Ogden CL, Carroll MD, Curtin LR, McDowell MA, Tabak CJ, et al. (2006) Prevalence of overweight and obesity in the United States, 1999-2004. JAMA 295(13): 1549-1555.

13. Angulo P (2002) Nonalcoholic fatty liver disease. N Engl J Med 346(16): 1221-1231.

14. Ayyad C, Andersen T (2000) Long-term efficacy of dietary treatment of obesity: a systematic review of studies published between 1931 and 1999. Obes Rev 1(2): 113-119.

15. Day CP, James OF (1998) Steatohepatitis: a tale of two "hits"? Gastroenterology 114(4): 842-845.

16. Koek GH, Liedorp PR, Bast A (2011) The role of oxidative stress in nonalcoholic steatohepatitis. Clin Chim Acta 412(15-16): 1297-1305.

17. Postic C, Girard J (2008) Contribution of de novo fatty acid synthesis to hepatic steatosis and insulin resistance: lessons from genetically engineered mice. J Clin Invest 118(3): 829-838.

18. Sanchez Alcazar JA, Schneider E, Martinez MA, Carmona P, Hernandez Munoz I, et al. (2000) Tumor necrosis factor-alpha increases the steady-state reduction of Cytochrome of the mitochondrial respiratory chain in metabolically inhibited L929 cells. J Biol Chem 275(18): 13353-13361.

19. Martín Domínguez V, González Casas R, Mendoza Jiménez Ridruejo J, García Buey L, Moreno Otero R (2013) Pathogenesis, diagnosis and treatment of non-alcoholic fatty liver disease. Rev Esp Enferm Dig 105(7): 409-420.

20. Shah K, Stufflebam A, Hilton TN, Sinacore DR, Klein S, et al. (2009) Diet and exercise interventions reduce intrahepatic fat content and improve insulin sensitivity in obese older adults. Obesity (Silver Spring) 17 (12): 2162-2168.

21. Palmer M, Schaffner F (1990) Effect of weight reduction on hepatic abnormalities in overweight patients. Gastroenterology 99(5): 14081413.

22. Yancy WS, Olsen MK, Guyton JR, Bakst RP, Westman EC (2004) A lowcarbohydrate, ketogenic diet versus a low-fat diet to treat obesity and hyperlipidemia: a randomized, controlled trial, Ann Intern Med 140(10): 769-777.

23. Promrat K, Kleiner DE, Niemeier HM, Jackvony E, Kearns M, et al (2010) Randomized controlled trial testing the effects of weight loss on nonalcoholic steatohepatitis, Hepatology 51(1): 121-129.

24. Oh S, Shida T, Yamagishi K, Tanaka K, So R, et al. (2015) Moderate to vigorous physical activity volume is an important factor for managing nonalcoholic fatty liver disease: a retrospective study. Hepatology 61(4): 1205-1215.

25. Starkie R, Ostrowski S, Jauffred S, Febbraio M, Pedersen B (2003) Exercise and IL-6 infusion inhibit endotoxin induced TNF-alpha production in humans. FASEB J 17(8): 884-886. 


\section{Current Research in Diabetes \& Obesity Journal}

26. Jankord R, Jemiolo B (2004) Influence of physical activity on serumIL-6 and IL-10 levels in healthy older men. Med Sci Sports Exerc 36(6): 960964.

27. Kasapis C, Thompson P (2005) The effects of physical activity on serum C-reactive protein and inflammatory markers: a systematic review. J Am Coll Cardiol 45(10): 1563-1569.

28. American College of Sports Medicine (2005) Guidelines for graded exercise testing and exercise prescription. Lea \&Febiger, Philadelphia, USA.

29. World Health Organization (1990) Diet, nutrition and the prevention of chronic diseases. London, HMSO (Tech. Rep. Ser., no. 797)

30. Sciacqua A, Candigliota M, Ceravolo R, Scozzafava A, Sinopoli F, et al (2003) Weight loss in combination with physical activity improves endothelial dysfunction in human obesity. Diabetes Care 26(6): 1673 1678.

31. Murakami T, Horigome H, Tanaka K, Nakata Y, Ohkawara K, et al. (2007) Impact of weight reduction on production of platelet-derived microparticles and fibrinolytic parameters in obesity. Thromb Res 119(1): 45-53.

32. Pacana T, Sanyal AJ (2015) Recent advances in understanding/man agement of non-alcoholic steatohepatitis. F1000Prime Rep 7: 28.

33. Koek G, Liedorp P, Bast A (2011) The role of oxidative stress in non-alcoholic steatohepatitis. Clin Chim Acta 412(15-16): 1297-1305.

34. Dandona P, Weinstock R, Thusu K, Abdel Rahman E, Aljada A, et al. (1998) Tumor necrosis factor- $\alpha$ in serum of obese patients: fall with weight loss. J Clin Endocrinol Metab 83(8): 2907-2910.

35. Sandoval D, Davis S (2003) Leptin, Metabolic control and regulation. J Diabetes Complications 17(2): 108-113.

36. Balagopal P, George D, Patton N, Yarandi H, Roberts WL, et al. (2005) Lifestyle-only intervention attenuates the inflammatory state associated with obesity: a randomized controlled study in adolescents. J Pediatr 146(3): 342-348.
37. Sheu WH, Chang TM, Lee WJ, Ou HC, Wu CM, et al. (2008) Effect of weight loss on pro-inflammatory state of mononuclear cells in obese women. Obesity (Silver Spring) 16(5): 1033-1038.

38. Selvin E, Paynter NP, Erlinger TP (2007) The effect of weight loss on C-reactive protein: a systematic review. Arch Intern Med 167(1): 3139.

39. You T, Nicklas B (2006) Chronic inflammation: role of adipose tissue and modulation by weight loss. Curr Diabetes Rev 2(1): 29-37.

40. Nicklas B, You T, Pahor M (2005) Behavioural treatments for chronic systemic inflammation: effects of dietary weight loss and exercise training. CMAJ 172(9): 1199-1209.

41. Lang HF, Chou CY, Sheu WH, Lin JY (2011) Weight loss increased serum adiponectin but decreased lipid levels in obese subjects whose body mass index was lower than $30 \mathrm{~kg} / \mathrm{m}^{2}$. Nutr Res 31(5): 378-386.

42. Mathur M, Pedersen BK (2008) Exercise as a mean to control lowgrade inflammation. Mediators Inflamm 2008: 109502.

43. Timmerman K, Flynn M, Coen P, Markofski M, Pence B (2008) Exercise training-induced lowering of inflammatory (CD14+CD16+) monocytes: a role in the anti-inflammatory influence of exercise? Leukoc Biol 84(5): 1271-1278.

44. Wang J, Song H, Tang X, Yang Y, Vieira VJ, et al. (2012) Effect of exercise training intensity on murine Tregulatory cells and vaccination response. Scand J Med Sci Sports 22(5): 643-652.

45. Roberts CK, Won D, Pruthi S, Lin SS, Barnard RJ (2006) Effect of a diet and exercise intervention on oxidative stress, inflammation and monocyte adhesion in diabetic men. Diabetes Res Clin Pract 73(3): 249-259.

46. Fernández Sánchez A, Madrigal Santillán E, Bautista M, Esquivel Soto J, Morales González A, et al. (2011) Inflammation, oxidative stress, and 544 obesity. Int J MolSci 12(5): 3117-3132. will reach you the below assets

- Quality Editorial service

- Swift Peer Review

- Reprints availability

- E-prints Service

- Manuscript Podcast for convenient understanding

- Global attainment for your research

- Manuscript accessibility in different formats ( Pdf, E-pub, Full Text, Audio)

- Unceasing customer service

Track the below URL for one-step submission https://juniperpublishers.com/online-submission.php 